\section{Dario Alpini, a pioneer of venous and lymphatics disorders of the inner ear}

On $3^{\text {rd }}$ of June 2017, Dr. Dario Alpini left us all. He would have been 59 years old in July.

His heart decided to surrender to the terrible disease that had hit him and his beautiful mind.

After five long years of struggle where he even found time to write and publish, the Scientific Community will miss him ever so much.

Dario dedicated most of his scientific work exploring the causes that provoked dizziness and vertigo and more recently joined with enthusiasm all the research that regarded chronic cerebrovascular venous insufficiency (CCSVI) finding and bridging, as he used to say, the gap between Ménière's disease and multiple sclerosis.

Some of his most recent works, as listed below, were under form of scientific papers while in other occasions as author and reviser of books. ${ }^{1-6}$

His Patients and Friends all loved him for his patience and presence, together with a wonderful temper and a friendly word for all. Those who knew him well also appreciated his capacity for intuitions and ideas.

We will miss the Man, the Doctor and the Friend.

Pietro Maria Bavera University of Milan, Italy pmbavera@icloud.com

\section{References}

1. Alpini DC, Bavera PM, Di Berardino F, et al. Bridging the gap between chronic cerebrospinal venous insufficiency and Ménière disease. Veins and Lymphatics 2016;5:5687.

2. Bavera PM, Di Berardino F, Cecconi P, et al. Chronic cerebro-spinal insufficiency in multiple sclerosis and Meniere disease: same background, different patterns? Veins and Lymphatics 2017;6:6533.

3. Alpini D, Bavera PM, Di Berardino F, et al. Bilateral sudden sensorineural hearing loss and chronic venous cerebrospinal insufficiency: a case report. Phlebology 2013;28:231-3.

4. Alpini D, Berardino FD, Mattei V, et al.

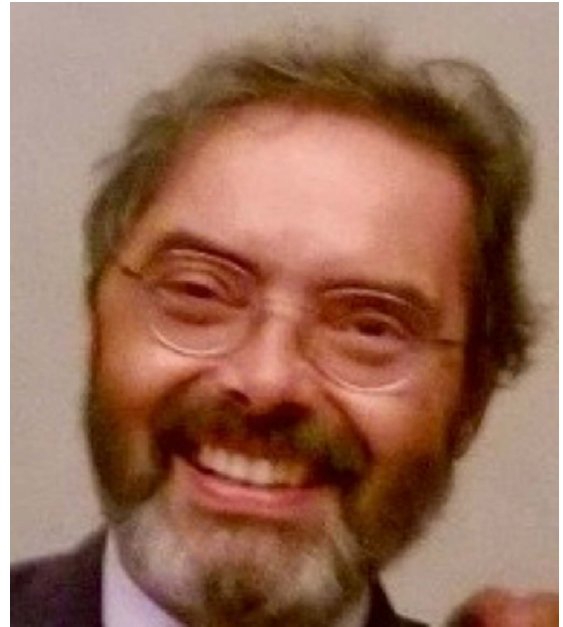

Characteristics of multiple sclerosis patient stance control disorders, measured by means of posturography and related to brainstem lesions. Audiol Res 2012;2:e9.

5. Di Berardino F, Alpini DC, Bavera PM, et al. Chronic cerebrospinal venous insufficiency in Ménière disease. Phlebology 2015;30:274-9.

6. Cesarani A, Alpini DC. Vertigo and dizziness rehabilitation. BerlinHeidelberg: Springer; 1999. 